\title{
The Effects of the Ageing Population on Healthcare Expenditure: A Comparative Study of China and India
}

\author{
NurHaiza Nordin ${ }^{1}$; NurNaddiaNordin ${ }^{2}$ NorAsma Ahmad ${ }^{3}$ \\ ${ }^{1,3}$ Department of Business and Finance \\ Faculty of Entrepreneurship and Business \\ University Malaysia Kelantan \\ Kelantan, Malaysia \\ ${ }^{2}$ Department of Economics \\ Faculty of Management and Muamalah \\ Selangor International Islamic University College \\ Bandar Seri Putra, Bangi, Selangor, Malaysia
}

haiza@umk.edu.my; naddia@kuis.edu.my;asma.a@umk.edu.my

\section{Abstract:}

The motivation of the study is to compare the impact of aging population on healthcare expenditure between China and India as demographic projection forecast that the percentage people above 65 years will be 26 percent by 2050. The used of long time series data of China and India from 1970 to 2011 helps us to identify the long run relationship between ageing population and healthcare expenditure using ARDL bound testing approach. The result of the bounds test showed that there is a stable, long-run relationship between the ageing population and healthcare expenditure, life expectancy, and GDPC. In fact, results revealed that the ageing population influences healthcare expenditure both in China and India. However, in the case of China the ageing population is a more dominant influence on healthcare expenditures because the total ageing in China is greater than that of the population in India.

Keywords: Ageing population, healthcare expenditure, China, India and ARDL model.

\section{Introduction}

Recently, a change in the demographic nature of the world population has attracted considerable attention from policy makers. Changes in the demographic nature affect the number of the ageing population. Population ageing is triggered by an increase in life expectancy rates and a decline in fertility rates, and it is a common feature of developed countries. According to demographic projections by the United Nations Population Division, the share of the total population aged 65 years and over in more developed regions is expected to grow from 14.3 percent in 2000 to 25.9 percent in 2050 , while the share of the total population aged 15-64 years is expected to decline from 67.4 percent in 2000 to 58.4 percent in $2050 .{ }^{1}$ One of the important related concerns are the effects of the

\footnotetext{
${ }^{1}$ The World Population Prospect: The 2004 Revision Population Database.
}

ageing population on healthcare expenditure. As physical and mental health tends to deteriorate with age, the elderly need much more healthcare including nursing and other services. In addition, the medical care required by older people involves relatively expensive technology and hospitalization.

Increases in healthcare expenditure are partly due to the advancements made in the treatments of chronic diseases and surgery. Ageing of the population is a challenge for medicine because of the growing number of elderly patients and the many implications of this; much comorbidity is very costly, as is the case with cardiovascular diseases, cancer, chronic renal disease and diabetes, and their respective complications. Expenditure on health is important for a country to ensure the health of its citizens. The increase in health expenditure causes much concern all over the world. Factor influencing healthcare spending 
is the percentage of elderly people. The old spend more on medical care than the young, and it is, therefore intuitively correct to assume that the aggregate health care rises with higher percentage of elderly population in the country.

Studies in Japan by Fujino (1987) showed that the elderly consume about 3.2 times more medical services than the average person. In addition Murthy and Ukpolo (1994) showed that ageing populations, it is one of the most significant determinants of healthcare expenditure. The increase of healthcare expenditure of ageing people is affected by health status; in turn, it will have an influence on the social security of elderly people. Thus, in regards to the aforementioned issue, this study attempted to empirically investigate the impact of aging on health expenditure in China and India.

China and India have many characteristics in common. Specifically, both are developing economies with large populations. Over the past 50 years, both countries have made substantial improvements in health, such as increased life expectancy, reduced infant mortality, and the eradication of several diseases. Despite these improvements, China's and India's health status still lags that of other populations in developed and developing countries. According to the international standard, a country with either 10 percent of the population over 60 or 7 percent of the population over 65 is considered to be an aging country. According to the National Bureau of Statistics of China, China became an ageing country with $7 \%$ of the population over 65 years old in 2000, and this percentage has been continuously rising. The forecast made by the Organization for Economic Co-operation Development (OECD) suggests that the ageing trend of China's population will speed up in the next few decades. In 2020, it is estimated that 11.61 percent of China's total population will be people who are over 65 years old. Figure 1 shows the total population and population growth in China and in India from 1970 to 2011. The total population in China is higher than that in India; in 1970, China's total population was 8.18 million and India's was 5.54 million, while in 2000 these figures increased to 1.26 billion in China and 1.05 billion in India. In 2011, the total population in China increased to 1.34 billion and 1.24 billion in India.

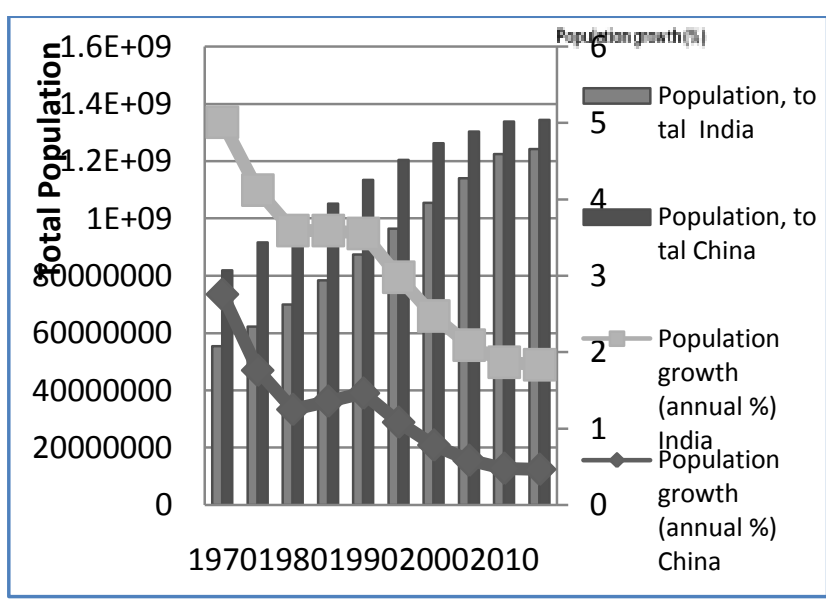

Figure 1: Total population and population growth in China and India in 1970 to 2011

\section{Source: World Bank Indicator}

The rapid fertility reduction associated with the one-child policy in China may potentially negatively impact older people, as they might not be able to rely on their children to take care of them. United Nations and Chinese government statistics in 1987 pointed out that by the year 2000 the population of individuals 60 years and older would be 127 million or 10.1 percent of the total population and 234 million or 16.4 percent in 2025. According to the projection, if the one child policy were maintained until the year 2000, 25 percent of China's population would be aged 65 years or older by 2040. China's older population, those over 65 , will likely swell to 330 million by 2050 from 110 million in 2010 India's current older population of 60 million is projected to exceed 227 million in 2050, an increase of nearly 280 percent from in 2010 Thus, this concludes that the ageing of China's population is greater than India's from 2010 to projection year 2050. Figure 2 shows the young and ageing populations in China and India from 1970 to 2011. The young population percentage of the total population decreased from 1970 to 2011 in both countries; however, India has a higher percentage of young population. The decrease in the young population is caused by the implementation of the population policies in China and India; at the same time, the decrease in the young population will increase the percentage of older people, especially in the future. From the figure, thepercentage of ageing people areincreasing slightly from year to year. In 1970, the ageing population in China was 3.95 
percent of the total population and 3.30 percent in India. In 1990, the percentage of the ageing population increased to 5.78 percent and 3.89 percent in China and India, respectively. At the end of 2011, this figure increased to 8.50 percent for China and 5.13 percent in India.

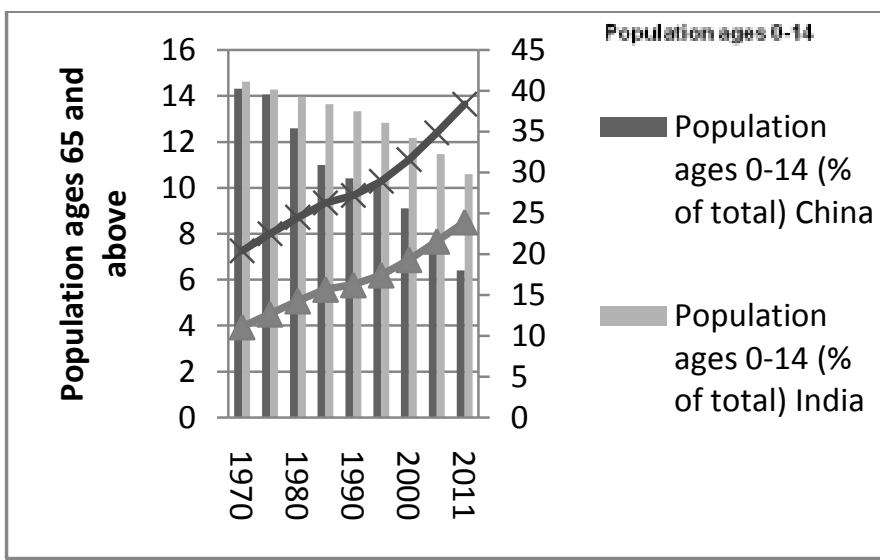

Figure 2: Population ages $0-14$ and population ages 65 and above for China and India from 1970 to 2011

\section{Source: World Bank Indicator}

With the economic and healthcare services development in China and India, life expectancy has been rising steadily in the past three decades. Total life expectancy in China could still rise,albeit at a relatively slower rate than in previous decades, in the next 40 years; and it will hit almost 80 in 2050 (China Healthcare Policy Study, 2011). With lower birth rates and extended life expectancy in China, it is widely believed that the country is becoming an aged society. For India, the life expectancy at birth rate for females and the mortality rate are less than 5. By 2025, an estimated 189 million Indians will be at least 60 years old, triple the number in 2004. The growing elderly population will place an enormous burden on India's healthcare infrastructure.

Expenditures on healthcare services represent a relatively modest share of China's GDP (5.16 percent in 2011), but they are higher there than in India (3.87 percent in 2011). (Refer to Figure 3.) The pace of GDP growth has been unprecedentedly rapid, however, and healthcare spending in China has increased during the reformation era,to 64.43 percent of spending in
2001. In 2002, with the beginning of governmentsubsidized health insurance for rural Chinese, the private spending constituted a little over half of China's total healthcare spending, much higher than that of many low and middle income countries.

The factor that is driving the growth of India's healthcare sector is a rise in both infectious and chronic diseases. This troubling trend can be attributed in part to substandard housing, inadequate water, sewerage and waste management systems, a crumbling public health infrastructure, and increased air travel. A vast amount of private capital will be required in the coming years to enhance and expand India's healthcare infrastructure to meet the needs of a growing population, which approximately \$US54per capita (4.05\% of GDP in 2010). When it comes to healthcare, the estimated 1.2 billion Indiansare split into two groups. The middle and upper classes, which generally live in the urban areas of India, have access to quality medical care;however, the majority of India lives below the poverty line in rural areas and has extremely limited access to medical care.

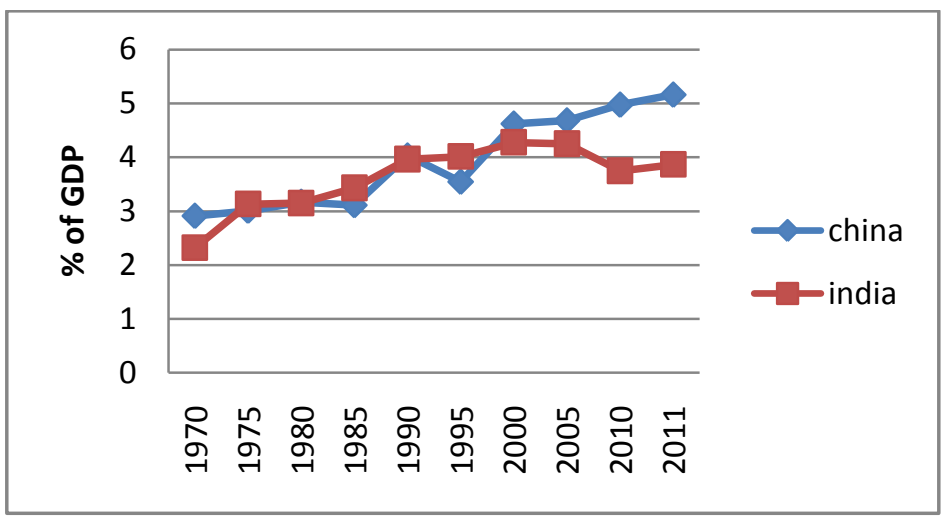

Figure 3: Total Healthcare Expenditure (\% of GDP) in China and India from 1970 to 2011

Source: World Development Indicator (WDI)

\subsection{Literature review}

Over the last 30 years, developed countries have experienced significant changes in the age composition of their populations. The relative numbers of the ageing population, in particular those 65 and above, have steadily increased and this trend is expected to continue over the upcoming decades. Academic and popular writers predict that population ageing will substantially 
affect social, political, and economic conditions in the developed world. Particularly, the consequences are expected to be pronounced for the healthcare sector, where population ageing is blamed for the steady growth of per capita healthcare expenditure (HCE) observed in most industrialized countries over the last 30 years. Due to the strong correlation between HCE and age, future population ageing is expected to result in a continued surge in HCE.

Matteo (2005) examines the determinants of real per capita health expenditures to assess the impact of age distribution, income and time. International, national and regional data is used to examine the drivers for health expenditure. The variables used are believed have effects on health expenditure. The positive drivers of health expenditure that includes per capita income, the proportion of the population either over the age 65 or under the age 15 , the public share of healthcare spending, urbanization, the amount of foreign aid and the number of physicians per capita. The result suggests that an ageing population driver up health expenditures, but the effects are relatively modest. The result indicates that it is not necessarily the proportion of the population greater than age 65 that is always responsible as the proportion aged 18-44 is also a positive and significant driver and the impact of time explains approximately two-thirds of the increase in health expenditures.

Lago-Penas, Cantarero-Prieto and Blazquez-Fernandez (2013) studied the relationship between GDP and healthcare expenditure. The hypothesis of these studies is that choices on healthcare expenditure do not adapt to changes in per capita GDP automatically. The result shows that the long-run income elasticity is close to unity, that health expenditure is more sensitive to per capita income cyclical movements that to trends, movements and that the adjustment to income changes in those countries with a higher share of private health expenditure over total expenditure are faster.

Concerning studied by Baltagi and Moscone (2010), Mehrara et al. (2010) and Liu et al. (2011). Baltagi and Moscone (2010) using data for 20 OECD countries, studied the nonstationarity and co-integration properties between healthcare expenditure and income, their findings suggest that healthcare is a necessity rather than a luxury. Similar to Mehrara et al. (2010) found that the income elasticity for all OECD members is 2.59. They also estimated that the income elasticity of health expenditure over time and across the countries has been rather unvarying. Liu et al. (2011) tested for structural breaks with panel, varying coefficient models, making an application to OECD health expenditure. They found a full-sample income elasticity of 1.603 .

Kildemoes et al., (2006) studied the impact of population ageing on future Danish drug expenditure. Population ageing is likely to place an increasing burden on future healthcare budgets. Several studies, however, demonstrate the impact of ageing on future hospital expenditures will be overestimated when not accounting for proximity to death. This is because the greater healthcare expenditure among the elderly is not only due to age per se, but due to the high cost of dying. This paper aim to estimate the impact of ageing Danish population on future total expenditures on out-ofhospital prescription drugs and to describe the association between the age and drug expenditure among survivors compared to that of decedents, and to evaluate the extent to which drug expenditure is increasing with proximity to death in the last 2 years of life. The result found that the ageing of the population per se is likely to increase future expenditure on prescription drugs. This predicted increase, however, is small compared to recently observed increases in drug expenditures.

Lin et al., (2010) studied on Taiwan healthcare system. Taiwan is one of the fastest aging countries in the world. Taiwan faced with the various impacts of population aging and developed various culturally appropriate strategies and has gained certain positive outcomes. Taiwan became an aging country when the elderly population exceeds $7 \%$ of the total population in 1993, an expected to become an aged country when the aged population exceeds $14 \%$ of the total population in 2017 (Executive Yuan, 2008). The government has developed various strategies to promote an age-friendly healthcare system. Health services are supported by National Health Insurance (NHI), which insurers over $97 \%$ of health are instituted. The current healthcare system has difficulties in caring for older patients with multiple commodities, complex care needs, functional impairments, and post-acute care needs. 
Taipei, an international metropolis with a wellpreserved tradition of filial piety in Chinese society, has developed various strategies to overcome the aforementioned barriers to an aged friendly healthcare system.

Breyer and Felder (2006) studied on the demographic impact on healthcare expenditure in Germany. Using a Swiss data set, derive age expenditure profiles for both genders, separately for persons in their last 4 years in life and for survivors, and this studied also applied to the projections of the age structure and mortality rates for the German population between 2002 and 2050. The morbidity is compressed at the end of life in such a way that a 60-year old in 2050 is as healthy as a 56-year old today if his life expectancy is 4 years higher. Result found that when calculate at constant prices, per capita health expenditure of Social Health Insurance is rising from year 2020 to 2050 when only the age structure of the population changes and everything else remain constant at the present level and with technology driven exogenous cost increase of 1 percent per annum.

Meijer (2013) found that changes in medical practices, in part resulting from technological progress and the relaxation of budgets, where the dominant drivers of acute healthcare expenditure growth in the Netherlands. This in line with evidence from other countries that identifies medical technology as the key driver of expenditure growth, for example, researched by Newhouse, 1992; Reinhardt, 2003; Dormont et al., 2006. While there is a discernible contribution of population ageing to spending growth, it is moderate: population ageing could explain 4 percentage points of the 38 percent growth in median real expenditure. However, its impact cannot be entirely isolated from that a technological progress and the relaxation of hospitals' budgets. Both developmentsseem to have disproportionately benefited the elderly given that expenditures on older groups rose more than those on younger groups.

Getzen (1992) investigated the relationship between the increase in the share of older people within the population and per capita HCE. By using cross-sectional and time-series data of 20 OECD countries from the period 1966-1988, he concluded that HCE in OECD countries is dominated by the macroeconomic effects of GNP growth. He concluded that without government budget constraints, population ageing would have caused per capita HCE to have increased in OECD countries.

Research by Cutler and Meara (1997), Mayhew (2000), and Robson (2001) found that the process of population ageing imposes pressure on the increase in medical expenditures; elderly people's medical expenditures are higher and rise faster than that of other age groups. Other studies by Shover, Topper, and Wise (1994) concluded that the increase in the medical expenditures of elderly people is affected by their health status; this has an influence on the social security of elderly people. The medical expenditure of elderly people in America is predicted to exceed the annuity revenue in 2020; then the process of population ageing will impose a dual burden on medical expenditure and the annuities. This impact which is partially from medical expenditures caused by population ageing is a negative burden; but it also presents opportunities and challenges.

Karatzas (2000) tested a number of hypotheses of rising healthcare expenditures, modeling real per capita US healthcare expenditures over the period 1962-1989 with health stock, demographic, and income variables. Karatzas constricted four models to explain rising healthcare spending, and each model focused on a different set of explanatory variables. One of the conclusions is that changes in economic, demographic, and health stock variables produce persistent changes in per capita real healthcare expenditure; these findings did not support the contention per capita real income is the only major determinant of per capita real healthcare spending. According to his results, a 1 percent increase in the portion of people over 65 in the economy will cause total per capita health expenditure to rise by 2.55 percent.

Zweifel, Felder, and Meiers (1999) used longitudinal data from a Swiss health insurer to analyze the relationship between healthcare expenditure and age over the last eight quarters of life of individuals who died during the period 1983-1992. They found that remaining lifetime was a highly significant predictor of healthcare expenditure, but that a person's calendar age was not statistically significant. They, therefore, 
concluded that the simple ageing of the population was possibly a "red herring" when looking for factors that influence the growth of healthcare expenditure.

Research by Meerding et al. (1998) found that healthcare costs are age dependent after high costs in the first year of life; they are lowest for children and rise slowly throughout adult life, exponentially after age 50. Another study by Bradford and Max (1996) found that annual costs for elderly healthcare are four to five times those in earlier times. Also, another number of studies by Colombier and Weber (2010), Labitz et al. (2003), Ruggeri (2002), OECD (2006), Pammolli et al. (2008), Ogawa et al. (2009), and Johnson and Teasdale (1999), among others, identified the population share of the elderly as a key driver of healthcare costs. For developing countries such as India, which is experiencing a gradual ageing with the proportion of the population aged 60 and above expected to increase from 7.7 percent in 2010 to 18.3 percent in 2050 (United Nations World Population Prospects, 2012), the aforementioned findings have alarming implications in meeting the population's healthcare needs. Forecasting the expected magnitude of the impending population ageing's monetary implications in India is crucial to evolve sustainable long-term healthcare costs and to project healthcare costs.

Marzouk (1991) studied on ageing population in Canada in which he attempted to allow for the uneven distribution of health spending per capita by age group, but also the likely impact of increases in per capita healthcare use among the elderly. He predicted that demographic shift and changes in utilization patterns were likely to result in a doubling of Canadian healthcare spending as a share of gross domestic product over approximately 40 years.

On the contrary, studies by Zweifel et al. (1999), Felder et al. (2000), and Seshamani and Gray (2004) have negated the view that populating ageing increases the burden of healthcare costs, controlling for proximity to death. The findings should serve as a wakeup call to stakeholders about the gravity of preparedness required to support the healthcare costs of India's gradually ageing population.
In China, medical expenditure has experienced a rapid and steady increase since 1978, from 2.93 percent of GDP in 1970 to 5.16 percent in 2010; the speed has far exceeded that of GDP since the 1990s. For example, the rising rate of medical expenditureswas 4.04 percent in 1996, while the figure for GDP was 10 percent in the same year (Yuxin\&Lexun, 1998). The growth in the elderly population will lead to additional increasesin total medical expenditure. This is based on the data and information published from the National Health Service Investigation in the "Year book of health in the People's Republic of China" (1993), "China population yearbook" (1998), and "China population statistic yearbook" (2003). Thus, based on analyses of the health status of elderly people in the last decade, we conducted further research into the effects of the ageing population on healthcare expenditure, whichwere accompanied by other factors, in India and China.

\subsection{Methods}

In this study, we employed time series data analysis. To examine the order of integration, autoregressive distributed lags (ARDL) or bounds test was used to examine the relation between exogenous and endogenous variables. In addition, a unit root test was used to test for stationary. The use of the bounds testing technique was based on the validations. First, Pesaran et al. (2001) supported the use of the ARDL model for the estimation of level relationship because the model suggested that once the order of ARDL has been recognized; the relationship can be estimated by OLS. Second, the bounds tests allowed a mixture of $I(1)$ and $I(0)$ variables as the regressors; that is, the order of integration of the appropriate variables was not necessarily the same. Therefore, the ARDL technique had the advantage of not requiring a specific identification of the order of the underlying data. Third, this technique was suitable for a small or finite sample size (Pesaran et al., 2001).

\subsection{Data description}

The empirical analysis was based on China and India. The time series data were annual and covered the period 1970-2011. The healthcare expenditure was in per capita GDP. We also 
gathered data from the following variables which have been identified in literature for their roles in determining healthcare expenditures: ageing population, life expectancy, GDPC, and number of hospital beds. The independent variables are divided for several indicators such as GDPC for the economic indicator, population as the demographic indicator, life expectancy as the health indicator and the total number of hospital beds as the healthcare infrastructure indicator. All data were obtained from the World Bank Indicator and the World Population Prospect 2012, and they were converted into a natural logarithmic form before the empirical analysis.

The proportion of the population aged 65 and above is classified as the elderly population. Aljunid(1997) stated that a few authors have provided some definition of aging, such as the regression of physiological function accompanied by advancement of age and the progressive accumulation of changes with time associated with or responsible, for the ever increasing susceptibility to disease and death with accompanying aging. On the other hand, Aljunid found a report made by the United Nations in 1993 that stated a country is said to be aged when at least 7 percent of the population is elderly. The elderly spend more on medical care than young people, so when the percentage of the elderly population in a country rises, then the aggregate healthcare spending rises as well.

Life expectancy at birth indicates the number of years a newborn infant will live if prevailing patterns of mortality at the time of birth stay the same throughout the infant's life. Guralnik (1991) and Fries (1993) found that as life expectancy increases, older people become more vulnerable to diseases and spend more on healthcare. The economic indicator, namely Gross domestic product (GDP) is a measure of the income and expenditures of an economy. According to Mankiw (1998), the GDP of a country is defined as the market value of all final goods and services produced within said country in a given time period. GDP is also considered to be the sum of value added at every stage of production of all final goods and services produced within a country in a given period of time. Many empirical studies have shown that gross domestic product has a strong influence on healthcare expenditure. For example, Gerdtham and Jonnson (1992) and Hitiris and Postnett (1992) used cross-sectional OECD data, and they reported that gross domestic product was one of the most important determinants of healthcare expenditure. The total number of beds in hospitals is a measurement of the healthcare infrastructure. An increase in the total number of beds is associated with higher healthcare expenditure. Hosoya (2013) found that the coefficient of total beds shows an expected but insignificant sign; thus, this variable has no impact on healthcare costs.

\subsection{Model Specification}

To examine the effects of the ageing population on healthcare expenditure, ARDL bounds testing as introduced by Pesaran et al. (2001) was used in the following model. The Healthcare Expenditure (HCE) percent of GDP was predetermined as the dependent variable, while the independent variable was the ageing population (AGEING) and the control variables were life expectancy (LE), gross domestic product per capita (GDPC), and number of hospital beds (BEDS).

The model specification was as follows:

$$
\begin{aligned}
H C E_{t}= & f\left(A G E I N G_{t}, L E_{t}, G D P C_{t}, B E D S_{t}\right) \\
H C E_{t}= & \beta_{0}+\beta_{1} A G E I N G_{t-1}+\beta_{2} L E_{t-1}+\beta_{3} G D P C_{t-1} \\
& +\beta_{4} B E D S_{t-1}+\mu_{t}
\end{aligned}
$$

For multiple regression analysis, the log likelihood function of this model can be written as:

$L N H C E_{t}=\beta_{0}+\beta_{1} L N A G E I N G_{t-1}+\beta_{2} L N L E_{t-1}$ $+\beta_{3} L N G D P C_{t-1}+\beta_{4} L N B E D S_{t-1}+\mu_{t}$ (3)

By using the autoregressive distributed lags (ARDL), the model is transformed into:

$$
\begin{aligned}
& \triangle L N H C E_{t} \\
& =\beta_{0}+\beta_{1} L_{N A G E I N G}+\beta_{2} L_{t N L E_{t-1}}+\beta_{3} L_{N G D P C} C_{t-1} \\
& +\beta_{4} L_{N B E D S_{t-1}}+\sum_{i=1}^{3} \beta_{5 i} \Delta L N A G E I N G_{t-1} \\
& ++\sum_{i=1}^{3} \beta_{6 i} \Delta L N L E_{t-1}+\sum_{i=1}^{3} \beta_{7 i} \Delta L N G D P C_{t-1} \\
& +\sum_{i=1}^{3} \beta_{8 i} \Delta L N B E D S_{t-1} \\
& +\mu_{t}
\end{aligned}
$$

Where: 
$H C E=$ Healthcare Expenditure (\% of GDP)

$A G E I N G=$ Ageing Population

LE= Life Expectancy

$G D P C=$ Gross Domestic Product per Capita

$B E D S=$ Total Number of Hospital Beds

$\Delta=$ First different operator

To examine the long-run relationship, bounds testing for cointegration based on critical values adopted from Pesaran et.al (2001) was used with the following null hypothesis (for no long-run relationship) and the alternative hypothesis (for a long-run relationship): $H_{0}=\beta_{1}=\beta_{2}=\beta_{3}=$ $\beta_{4}=0$ and $H_{A} \neq \beta_{1} \neq \beta_{2} \neq \beta_{3} \neq \beta_{4} \neq 0$

\subsection{Results and Discussions}

\subsection{Unit root test}

A unit root test was done for all variables using the Augmented Dickey Fuller (ADF) and Phillips-Perron tests to satisfy the pre-requisite condition of the dependent variable's being non stationary or containing a unit root in $\mathrm{I}(1)$ and stationary at $\mathrm{I}(0)$ as prescribed by Pesaran (2001).

The results of the unit root test are reported in Tables 1-4 for China and India. Tables 1 and 2 present the results of the ADF and Philips-Perron tests in China, while Tables 3 and 4 show results of these tests in India. The order of integration was tested at 1, 5, and 10 percent significance level, and the critical values were obtained from the Mackinnon (1991) Tables. The results were robust regardless of the lag length. They showed that after differencing the variables once, they were confirmed to be stationary. The ADF and PhillipsPerron tests applied to the first difference of the data series rejected the null hypothesis of nonstationarity for all the variables; therefore, it is worth concluding that all the variables used in this study were not $\mathrm{I}(2)$.

Table 1: ADF unit root tests results for stationary of the variables in China

\begin{tabular}{|c|c|c|c|c|}
\hline & Intercept & $\begin{array}{l}\text { Trend \& } \\
\text { Intercept }\end{array}$ & Intercept & $\begin{array}{l}\text { Trend \& } \\
\text { Intercept }\end{array}$ \\
\hline LNHCE & -0.3649 & $-3.640 * *$ & - & - \\
\hline (Health & $(0.0396)$ & $(0.1060)$ & $4.6128 * *$ & $4.5710 * *$ \\
\hline Expenditur & & & & \\
\hline e) & & & $(0.1562)$ & $(0.1583)$ \\
\hline LNAGEIN & -0.2929 & - & - & - \\
\hline $\begin{array}{l}\text { G } \\
\text { (Ageing }\end{array}$ & $(0.0002)$ & $\begin{array}{l}2.8813 * \\
* *\end{array}$ & $\begin{array}{l}2.6013 * * \\
*\end{array}$ & $\begin{array}{l}2.5436 * * \\
*\end{array}$ \\
\hline Population) & & $(0.0032)$ & $(0.0109)$ & $(0.0112)$ \\
\hline LNLE & -0.2929 & -1.9157 & - & - \\
\hline (Life & $(0.0004$ & $(0.0082$ & $2.5518 *$ & $2.5023^{*}$ \\
\hline Expectanc & ) & ) & $* *$ & $* *$ \\
\hline y) & & & $(0.0170)$ & $(0.0175)$ \\
\hline LNGDPC & 3.2171 & 0.3022 & - & - \\
\hline (Gross & $(0.0125)$ & $(0.0497)$ & $4.9351 * *$ & $4.0274 * *$ \\
\hline Domestic & & & & $*$ \\
\hline $\begin{array}{l}\text { Product per } \\
\text { capita) }\end{array}$ & & & $(0.1611)$ & $(0.2359)$ \\
\hline LNBEDS & - & - & - & - \\
\hline (Hospital & $2.6515^{*}$ & $2.7844^{*}$ & $2.6441 * *$ & $2.1980 * *$ \\
\hline beds) & & & & \\
\hline & $(0.0755)$ & $(0.1204)$ & $(0.0306)$ & $(0.0923)$ \\
\hline
\end{tabular}

Table 2: Phillips-Perron (PP) unit root test results for stationary of the variables for China

\begin{tabular}{|c|c|c|c|c|}
\hline \multirow[t]{2}{*}{ Variable } & \multicolumn{2}{|l|}{ Level } & \multicolumn{2}{|c|}{ First Difference } \\
\hline & Inte & $\begin{array}{l}\text { Trend \& } \\
\text { Intercept }\end{array}$ & & $\begin{array}{l}\text { Trend \& } \\
\text { Intercept }\end{array}$ \\
\hline LNHCE & -0.5595 & -2.7326 & 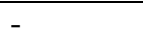 & - \\
\hline (Health & $(0.0396)$ & $(0.1085)$ & 4.570 & $4.5244 * *$ \\
\hline Expenditure & & & & \\
\hline ) & & & $(0.1562)$ & $(0.1583)$ \\
\hline LNAGEIN & -1.0883 & -2.2271 & - & - \\
\hline $\begin{array}{l}\text { G } \\
\text { (Ageing }\end{array}$ & $(0.0043)$ & $(0.0363)$ & $\begin{array}{l}2.7341 * * \\
*\end{array}$ & $\begin{array}{l}2.5812 * * \\
*\end{array}$ \\
\hline Population) & & & $(0.0418)$ & $(0.0438)$ \\
\hline LNLE & $-2.3 ?$ & - & - & - \\
\hline (Life & $(0.0070)$ & $4.8002 * *$ & $5.6596 * *$ & $5.1813^{* *}$ \\
\hline Expectanc & & & & \\
\hline y) & & $(0.0505)$ & $(0.0391)$ & $(0.0439)$ \\
\hline LNGDPC & 4.0442 & 0.4401 & - & - \\
\hline (Gross & $(0.0125)$ & $(0.0497)$ & $4.9963 * *$ & $5.0480 *$ \\
\hline Domestic & & & & \\
\hline $\begin{array}{l}\text { Product per } \\
\text { capita) }\end{array}$ & & & $(0.1611)$ & $(0.1646)$ \\
\hline LNBEDS & - & - & - & - \\
\hline (Hospital & $6.9803 * *$ & $7.6305 * *$ & $7.9977 * *$ & $8.1845 * *$ \\
\hline beds) & & & & \\
\hline & $(0.0911)$ & $(0.1351)$ & $(0.1615)$ & $(0.1633)$ \\
\hline
\end{tabular}

*** Significant at $1 \%$ level,** significant at 5\% level, *significant at $10 \%$ level. 
Table 3: ADF unit root tests results for stationarity of the variables for India

\begin{tabular}{lllll}
\hline Variable & Level & & \multicolumn{2}{l}{ First Difference } \\
\cline { 2 - 5 } & Intercept & $\begin{array}{l}\text { Trend \& } \\
\text { Intercept }\end{array}$ & Intercept & $\begin{array}{l}\text { Trend \& } \\
\text { Intercept }\end{array}$ \\
\hline LNHCE & - & - & - & - \\
(Health & $4.0965 * *$ & $4.4740^{*}$ & $4.8031^{* *}$ & $5.9055^{* *}$ \\
Expenditur & $*$ & $* *$ & $*$ & $*$ \\
e) & $(0.0333)$ & $(0.0682)$ & $(0.2256)$ & $(0.2236)$ \\
LNAGEIN & -0.0004 & - & - & - \\
G & $(0.0003)$ & $4.3230 *$ & $4.8352^{* *}$ & $5.7264 * *$ \\
(Ageing & & $* *$ & $*$ & $*$ \\
Population) & & $(0.0035)$ & $(0.0059)$ & $(0.0116)$ \\
LNLE & - & -5.0602 & - & - \\
(Life & $5.1628 *$ & $(0.0035$ & $6.3200 *$ & $6.0005 *$ \\
Expectanc & $* *$ & ) & $* *$ & $* *$ \\
y) & $(0.0003)$ & & $(0.0046)$ & $(0.0255)$ \\
LNGDPC & 0.8526 & -0.4690 & - & - \\
(Gross & $(0.0205)$ & $(0.0737)$ & $5.7575 * *$ & $5.8294 * *$ \\
Domestic & & & $*$ & $*$ \\
Product per & & & $(0.1618)$ & $(0.1642)$ \\
capita) & & & & \\
LNBEDS & - & & & - \\
(Hospital & $3.3498 *$ & $3.5764 *$ & $3.7436 * *$ & $4.4596^{* *}$ \\
beds) & $*$ & $* *$ & $*$ & $*$ \\
& $(0.0528)$ & $(0.0818)$ & $(0.1862)$ & $(0.1858)$ \\
& & & & \\
\hline
\end{tabular}

*** Significant at $1 \%$ level,** significant at 5\% level, *significant at $10 \%$ level.

Table 4: Phillips-Perron (PP) unit root test results for stationary of the variables for India

\begin{tabular}{|c|c|c|c|c|}
\hline \multirow[t]{2}{*}{ Variable } & Level & & First Diff & nce \\
\hline & Intercept & $\begin{array}{l}\text { Trend \& } \\
\text { Intercept }\end{array}$ & Intercept & \\
\hline
\end{tabular}

\begin{tabular}{lllll}
\hline LNHCE & - & - & - & - \\
(Health & $4.0371 * *$ & $4.5248 * *$ & $5.7673 * *$ & $6.2948 * *$ \\
Expenditure & $*$ & $*$ & $*$ & $*$ \\
) & $(0.0333)$ & $(0.0682)$ & $(0.1469)$ & $(0.1597)$ \\
LNAGEIN & 2.2145 & - & - & - \\
G & & $2.1964 * *$ & $3.0274 * *$ & $3.4811 * *$ \\
(Ageing & & $* .0081)$ & $*$ & $*$ \\
Population) & & $(0.0194)$ & $(0.0306)$ & $(0.0422)$ \\
LNLE & - & - & - & - \\
(Life & $*$ & $*$ & $* 1890 * *$ & $5.5787 * *$ \\
Expectanc & & & & $*$ \\
y) & $(0.0035)$ & $(0.0145)$ & $(0.0187)$ & $(0.0284)$ \\
& & & &
\end{tabular}

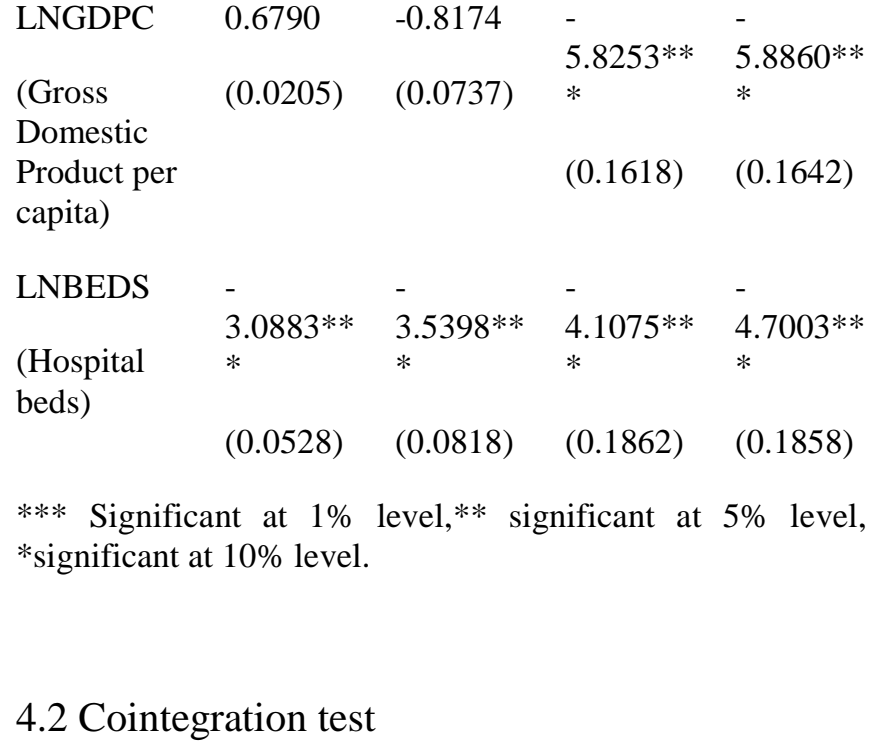

\subsection{Cointegration test}

The next step is to investigate whether healthcare expenditure, population ageing, life expectancy, GDPC, and number of hospital beds shared a common long-run relationship. To achieve this, we tested the presence of the longrun relationship in equation (4). Before that, to determine the optimal lag length of the variables, several lag selection criteria, such as the Akaike Information Criterion (AIC) and the Schwarz Info Criterion (SIC), were utilized. By using SIC, we found that the optimal lag was 1 for this exercise. We determined that there was a long-run relationship between the variables when the healthcare expenditure was a dependent variable because the F-statistic was 8.272 for China and 6.683 for India. Both F-statistic values were higher than the upper bound critical value at 5.532 percent at the 1 percent significance level based on Narayan (2004). This implies that the null hypothesis of no cointegration among the variables in the equation (4) cannot be accepted. The diagnostic test result of the equation (4) is displayed in Table 5.

Table 5: Bounds Test for Cointegration Analysis Based on Equation (4)

\begin{tabular}{|c|c|c|c|c|c|c|}
\hline & \multicolumn{2}{|c|}{$\begin{array}{c}10 \text { percent } \\
\text { level }\end{array}$} & \multicolumn{2}{|c|}{$\begin{array}{l}5 \text { percent } \\
\text { level }\end{array}$} & \multicolumn{2}{|c|}{$\begin{array}{c}1 \text { percent } \\
\text { level }\end{array}$} \\
\hline $\mathrm{k}$ & $I(0)$ & $I(1)$ & $I(0)$ & $I(1)$ & $I(0)$ & $I(1)$ \\
\hline 4 & 2.69 & 3.89 & 3.27 & 4.63 & 4.59 & 6.36 \\
\hline & 6 & 8 & 6 & 0 & 0 & 8 \\
\hline $\begin{array}{l}\text { alculat } \\
\text { d F- }\end{array}$ & & & & & & \\
\hline
\end{tabular}

statistic

Notes: The reported bounds critical values are taken from Narayan (2004), Table C[III].kis the number of regressors 
4.3 The Long-run and short-run estimation coefficients

The estimated of long-run coefficient for healthcare expenditure with respect to population ageing, life expectancy, the GDPC and the number of the hospital beds is presented in Table 6 .

Table 6: Long-run coefficient based on the ARDL model

\begin{tabular}{lll}
\hline \multicolumn{1}{c}{ Variable } & CHINA & INDIA \\
& & \\
\hline Ageing population & $1.8905 * *$ & $0.2701 * *$ \\
(AGEING) & $(1.7989)$ & $(1.2001)$ \\
Life Expectancy (LE) & $10.7686^{* * *}$ & $1.4805 * *$ \\
& $(2.6154)$ & $(1.8294)$ \\
Gross Domestic Product per & $0.0567 * * *$ & $0.1477 * *$ \\
Capita (GDPC) & $(0.8524)$ & $(1.0032)$ \\
& & \\
Hospital beds (BEDS) & $0.2820 *$ & -0.2171 \\
& $(1.7411)$ & $(-1.2247)$ \\
\hline *** Significant at 1\% level,** significant at 5\% level, \\
*significant at 10\% level. & &
\end{tabular}

All variables are significant at least at the 10 percent level for both China and India, except for the number of hospital beds for India. The results also reveal that our hypothesized variables, namely ageing, positively affect healthcare expenditure in both China and India. The effect in China, however, is much larger than in India. These findings support the hypothesis that ageing people account for a larger portion of healthcare expenditure because they are not participating in the labor market, however, as they aged the need to spend on medication and consultation on health is much higher compared to younger people. From the results, a 10 percent increase in the number of ageing people is estimated to increase healthcare expenditure in China and India 19 and 2.7 percent, respectively.

The results for life expectancy were positive for both China and India, and they were significant at the 1 percent level; this means that life expectancy is a good indicator for healthcare expenditure. In China, a 1 percent increase in life expectancy will increase healthcare expenditures by 10.76 percent. For India, the result for life expectancy was 1.48 percent, which means that a 1 percent increase in life expectancy will increase healthcare expenditures by 1.48 percent. Life expectancy in China shows a higher increase in healthcare expenditure than in India because it is 75 years for people in China and only 66.7 years in India. People in China live longer lives, and total ageing is also larger; thus, the ageing population will place greater demands on healthcare expenditure.

The results show that GDP per capita as an economic indicator has a positive and significant influence on healthcare expenditure. The result for GDPC in China is 0.0567 percent and 0.1477 percent in India. Both of the results are significant at the 1 percent level' and these findings mean that an increase in GDPC also will increase healthcare expenditure. This supported by previous literature such as Behesshti and Sojoudi (2008); Gerdtham and Lothgren (2000) and Clemente et al. (2004) that showed that there is a long-term relationship between total healthcare expenditure and GDP. Finally, our results for total number of hospital beds are positive and significant at the 10 percent level for China; however the result in India is negative insignificant. The numbers of hospital beds proxy for healthcare indicators play important role in China compared to India. From the result, a 10 percent increase in total beds in hospitals in China will increase Chinese healthcare expenditures by 2.8 percent. In India, however, the total number of beds in hospitals does not have a relationship with health expenditure.

To test the ARDL model, we applied a series of diagnostic tests and the result report in Table 7. It is clear that from the Table 7 that the model is clear from basic econometric problems, for example serial correlation, heteroscedasticity, normality and functional form. 
Table 7: Diagnostic Test of the Effects of Population on Healthcare Expenditure

\begin{tabular}{lcc}
\hline \multicolumn{1}{c}{ Test } & MODEL & MODEL \\
& WITH & WITH \\
& AGEING & AGEING \\
& F-Statistic & F-Statistic \\
& (P-value) & (P-value) \\
& China & India \\
& & \\
\hline Jarque-Bera & 2.1394 & 2.8849 \\
Normality Test & $(0.3431)$ & $(0.2363)$ \\
LM Test & 7.1427 & 0.6717 \\
& $(0.0043)$ & $(0.5206)$ \\
Heteroscedasticity & 1.4880 & 2.4309 \\
Test & $(0.0900)$ & $(0.0274)$ \\
ARCH Test & 1.5514 & 0.1987 \\
& $(0.2210)$ & $(0.6587)$ \\
Ramsey RESET Test & 0.0392 & 0.3732 \\
& $(0.1448)$ & $(0.1470)$ \\
\hline
\end{tabular}

Results for the short-run estimation coefficient are reported in Table 8 . The estimated coefficient for ECM must be a negative value, and it confirms that there is no problem in the long-run equilibrium relation between the independent and dependent variables. Results for the ECM confirm that both China and India are negative values and have a relationship between the dependent and independent variables; they are significant at the 5 percent level in China and at the 10 percent level in India. Results for the short-run coefficient indicate that the ageing population has a positive relationship with healthcare expenditure, and it is significant at the 1 percent level for both countries. This finding also confirms that the ageing population increases healthcare expenditure in the short run. Besides that, the other variables also indicate positive and significant relationships with dependent variables, except for total number of hospital beds. Results for hospital beds for both countries show a negative relationship, but they are statistically significant at the 5 percent level. From these results, we can conclude that the ageing population has a positive relationship with healthcare expenditure; an increase in the ageing population will increase total healthcare expenditure both in the long-run and short-run coefficients.

Table 8: Results for short-run estimation coefficient for China and India

\begin{tabular}{lll}
\hline Variable & CHINA & INDIA \\
& & \\
\hline ECM & $-1.5205^{* *}$ & $-2.5606^{*}$ \\
& $(-1.1468)$ & $(-0.0109)$ \\
Ageing population & $1.5476 * * *$ & $2.4394 * * *$ \\
(AGEING) & $(1.0407)$ & $(1.0068)$ \\
Life Expectancy (LE) & $1.5253^{*}$ & $2.6148^{* *}$ \\
& $(3.9117)$ & $(0.9415)$ \\
Gross Domestic Product per & $0.1241 * * *$ & $0.0216^{* * *}$ \\
Capita (GDPC) & $(1.3025)$ & $(0.2565)$ \\
& & \\
Hospital beds (BEDS) & $-0.0212 * *$ & $-0.0946 * *$ \\
& $(-0.2417)$ & $(-1.9346)$ \\
\hline *** Significant at 1\% level,** significant & at $5 \%$ level, \\
*significant at 10\% level. & \multicolumn{2}{c}{}
\end{tabular}

\subsection{Conclusion and Recommendations}

This paper aims to examine the relationship between the ageing population and healthcare expenditure both in the short-run and long-run estimation in China and India, by using time series data on healthcare expenditure, the ageing population and three control variables: life expectancy, GDPC, and hospital beds. The results confirmed that both in short-run and long-run estimations, the ageing population have a relationship with healthcare expenditure. The ageing population clearly shows relatively higher healthcare expenditure in the older-aged for China and India. China and India have a large ageing population; therefore, total healthcare expenditure is higher among the aged there, while India has a smaller ageing population. In China and India as an increasing absolute number of elderly will inevitably increase healthcare expenditure. The growing enlarges the total patient pool the healthcare market because of China and India are facing an aging society, unfortunately, diseases, especially chronic diseases affect older adults disproportionately, and as a result of an aging population, the country will be increasingly pressured to handle a growing sick population. Because many adults and older-age health problem were rooted in early life experiences and living condition, ensuring good child health can yields benefits for older people. In the meantime, generations of children and young adults who grew up in poverty and ill health in China and India will be entering old age in coming decades, potentially increasing the health burden of the older population in these countries. 
The potential for an active, healthy old age is tempered by one of the most daunting and potentially costly consequences of ever-longer life expectancy; the increase in people with dementia, especially Alzheimer's disease. Most dementia patients eventually need constant care and help with the most basic activities of daily living, creating a heavy economic and social burden. Prevalence of dementia rises sharply with age, an estimated 25-30 percent of people aged 85 or older have dementia. Without continuing declines in death rates among older people, the proportion aged 80 or older is rising quickly and more people are living past 100 . The limits of life expectancy and lifespan are not as obvious as once thought. And there is mounting evidence from crossnational data that with appropriate policies and programs people can remain healthy and independent well into old age and can continue to contribute to their community areas.

The Chinese government clearly understands the magnitude of the problem and has articulated its commitment to closing the significant gaps in the healthcare sector and has emphasized gaps in the healthcare sector and has emphasized the need for public and private sector cooperation. The gap between the need for healthcare services and the capabilities of current health insurance and delivery system is still immense. The government's commitment to address the current issues in the healthcare sector in apparent through candid acknowledgement. The government has already allocated to move investment to improve public health and rural health services; placed emphasis on controlling healthcare costs; implemented initiatives to improve hospital management to raise quality of patient care; and developed plans to establish and build a national health infrastructure.

The policies aimed at encouraging healthcare expenses and institutions, however, are required to build a healthier and more productive society to support China's and India's economic growth and development. In addition, the government should minimize the gap of the unequal distribution of healthcare among people, by taking into consideration the spread of emerging chronic diseases and assuring the quality and performance of the healthcare supply both in China and India. In addition, state funding should be increased for healthcare provision, public health, and health insurance schemes. The economies of both China and India are booming; this should not be at the expense of the poor and vulnerable in their societies. Both governments need to modify their predominantly neo-liberalist economic emphasis to ensure that state intervention in health is a sufficient proportion of GDP. China and India are vast in size and have large rural populations, in addition to huge urban centers. Thus, the development of effective partnerships between different spatial levels of health provision, from village to city, is essential.

Future research can consider other determinants of healthcare expenditure, such as technological progress and relative price; demographic indicators such as total population, population growth, and young population; health indicators such as birth rate, death rate, and infant mortality rate; and healthcare infrastructure such as private healthcare, public healthcare, and total number of physicians. The structure of this combination of factors has been the center of debate over whether increasing healthcare expenditure is influenced from the other factors. A larger data set and using another approach may also be beneficial to future research.

\section{References}

Colombier, C., \& Weber, W. (2011). Projecting Health Care Expenditure in Switzerland: Further Evidence Against the "Red-Herring" Hypothesis. International Journal Health Plan, Manage, 26, 246-263.

Cutler, D. M., \&Meara. (1997). The Medical Cost of the Young and Old: A Forty Year Perspective. NBER working paper 6114.National Bureau of Economic Research, Cambridge, MA, USA.

Department of Economic and Social Affairs, Population Division, Population Estimates and Projection Section. United Nations World Population Prospect 2012: The 2012 Revision.

Felder, S., Meier, M., and Schmitt, H. (2000), Health Care Expenditure in Last Month of Life, Journal of Health Economics, 19, pp. 679-695. 
Fujino,S., (1987). Health Economics in Japan: Prospect for the Future. In: Smith G.T., ed,. Health Economics: Prospect for the Future. London; New York: Croom Helm cited in Huang S.L. (2004). Factors Influencing Healthcare Spending in Singapore: A Regression Model. International Journal of the Computer, the Internet and Management Vol.12 No.3, pp. 51-62.

Getzen, T. E. (1992). Population Aging and the Growth of Health Expenditures. Journal of Gerontology: Social Sciences, 47(3), S98104.

Hitiris, T. and Posnett, J., (1992) The Determinant and Effect of Health Expenditure in Developing Countries, Journal of Health Economics, Vol. 11, pp. 173-181.

IIPS (International Institute for Population Science). (2000). National Family Health Survey 1998-1999.

Johnston, G., \& Teasdale, A. (1999).Population Ageing and Health Spending 50-years projection. Ministry of Health Wellington, New Zealand Occasional Paper No.2.

Karatzas, G. (1992). Determinants of Health Expenditure in Greece in the Post War Period.An Empirical Investigation. International Review of Economic and Business, XXXIX(1).

Lubitz, J. D., \& Riley, G. F. (1993). Trends in Medicare Payment in the Last Year of Life. New England Journal of Medicine, 328, 1092-1096.

Liu, X., \& Mills, A. (2000). Financing reforms of public health services in India and China: lesson from other nations. Social Science \& Medicine, 54, 1691-1698.

OECD (2006) Projecting OECD Health and LongTerm Care Expenditure: What Are the Main Drivers? OECD Economics Department Working Papers, No. 477. OECD Publishing.

Marzouk, M.S. (1991). Aging, Age-Specific Health Care Costs and the Future Health Care Burden in Canada. Canadian Public Policy, Vol. XVII:4 pp 490-506.
Mayhew, L. (2000). Health and Elderly Care Expenditure in an Aging World. IIASA Working paper RR-00-21. International Institute for Applied System Analysis.

Meerding, W. J., Bonneux, L., Polder, J. J., Koomanschap, M. A., \& Van Der Maas, P. J. (1998). Demographic and Epidemiological Determinants of Healthcare Cost in Netherlands: Cost of Illness Study. British Medical Journal, 317(7151), 111-115.

Meng, Q., Shi, G., Yang, H., Gonzalez-Block, M., \& Blas, E. (2004).Health Policy and System Research in China. UNICEF/UNDP/World Bank/WHO Special Programme for research training in tropical disease (TDR). China Health Economic Institute, WHO China.

MoHFW (Ministry of Health and Family Welfare).(2005a). Health Information of India.

Murthy, N.R.V. and Ukpolo, V. (1994). Aggregate Helath Care Expenditure in the United States: Evidence from Cointegration test, Applied Economics 26(8), 797-802.

Narayan, P.K. (2005). The Saving and Investment Nexus for China: Evidence from Cointegration tests. Applied Economics, 37, 1979-1990.

Ogawa, Naohiro, Amonthep, C., \&Rikiya, M. (2009). Some New Insight into the Demographic Transition and Changing Age Structure in the ESCAP region. Asia- Pacific Population Journal (Bangkok), 24(1), 87116.

Pammolli, F., Riccaboni, M., \&Magazzini, L. (2008). The Sustainability of European Health Care System: Beyond Income and Ageing. University a DegliStudi Di Verona, working paper, October 2008, 52.

Pesaran, M. H., Shin, Y. \& Smith, R. J. (2001).Bound Testing Approaches to the Analysis of Level Relationships. Journal of Applied Econometrics, 16(3), 289-326.

Robson, William. B.P. (2001). Will the Baby Boomers Bust the Health Budget? Demographic Change and Health Care 
Financing Reform. C.D. Howe Institute Commentary, 148. Toronto.

Ruggeri, J. (2002). Population Ageing, Health Care Spending and Sustainability: Do we really have a crisis? Caledon Institute for Social Policy.

Seshamani, M., \& Gray, A. (2004). Ageing and Health-Care Expenditure: The Red Herring argument Revisited. Health Economics, 13, 303-314.

Shover, J. B., Topper, W. D., \& Wise, D.A. (1994).The Impact of the Demographic Transition on Government Spending.In Wise D.A., editor, Studies in the Economics of Aging. Chicago; London: University of Chicago Press.
Zweifel, P., Felder, S., \&Meiers, M. (1999). Ageing of population and Health Care Expenditure: A Red Herring? Health Economics, 8, 485-496.

Yuxin, Z. \&Lexun, D. (1998).Analysis on China Health Account Assessment for the Year of 1996. Chinese Health Economics, 17(12), 28-29.

William. B.P. Robson, 2001. Will the baby boomers bust the Health Budget? Demographic change and healthcare financing reform.C.D. Howe Institute Commentary, 148. Toronto.

Zhao, Yuxin, \& Du, Lexun, 1998. Analysis on China health account assessment for the Year of 1996. Chinese Health Economics, 17(12), 28-29. 